\title{
Fairness, generosity and conditionality in the welfare system: The case of UK disability benefits
}

Elliott Johnson ${ }^{1}$, Daniel Nettle ${ }^{2 *}$

1. Lancaster University, Lancaster UK; e.johnson7@lancaster.ac.uk

2. Newcastle University, Newcastle UK; daniel.nettle@ncl.ac.uk

* To whom correspondence should be addressed.

This is an Author's Original Manuscript (AOM) of an article published by Bristol University Press in Global Discourse on 05 October 2020, available online: https://doi.org/10.1332/204378920X15989751152011.

Abstract: This paper represents a collaboration between a policy researcher and a behavioural scientist who studies cooperation. Our goal was to develop a shared understanding of one particular policy topic, the reforms to the UK system of disability benefits initiated during the last term of the New Labour Government and accelerated under the Conservative-led administrations since 2010. These reforms introduced much stronger focus on conditionality and assessment, aiming to reduce the cost of the benefit by identifying and removing 'cheaters' or 'undeserving' recipients from the system. The reforms have failed by even their own stated goals. Here, we seek to understand why they seemed appealing and intuitively likely to succeed. We argue that humans are vigilant cooperators, sensitive to cues of need in others, but also highly susceptible to the idea that others are cheating. This vigilance is particularly marked where they lack a reassuring stream of direct personal evidence to the contrary. The vigilance of human cooperative psychology makes ideas of greater conditionality and punishment easy for politicians to conceive of and sell. However, set against this, there are principles that can be used and successfully appealed to in advocating greater generosity in welfare systems. These include the fundamental social similarity of recipients and nonrecipients, and the idea that resources are not generated individually but represent the common windfall of a whole group.

Keywords: disability, welfare, cooperation, generosity, vigilance

\section{Key messages:}

- Humans are vigilant co-operators, motivated to help others, but attuned to cues of cheating.

- Vigilant cooperation drives popular intuitions about how welfare systems should work.

- This can be illustrated by examining changes to UK disability benefits.

- Appealing to popular intuitions does not necessarily lead to optimal policy making. 


\section{Introduction}

The gap between theory and empirical evidence on the one hand, and the development and deployment of policy on the other, is perhaps more publicised now than ever. But rejection of expert knowledge and pursuit of 'electability' have been key features of UK Government, and other governments, at least since the breakdown of the post-war consensus in the late 1970s. Eras in which 'evidence-based policy' were overtly praised were by no means immune. In 2009, Professor David Nutt, chair of the Advisory Committee on the Misuse of Drugs, was sacked by then Home Secretary, Alan Johnson, after he accused ministers of 'devaluing and distorting' scientific evidence in ignoring the advice of the Committee and increasing the penalties associated with cannabis possession (Travis 2009). Johnson argued Nutt could not 'be both a government adviser and a campaigner against government policy' (Johnson 2009) even, it seems, when that very policy stood in contradiction to expert advice.

It is in areas that are presumed contentious among the electorate that government appears to struggle most to put aside considerations about electability and pursue the policy direction identified by the evidence as optimal. Few areas of policy have been more contentious during the last decade of austerity than welfare. The UK Conservative and Liberal Democrat Coalition Government of 2010-2015 instituted a series of reforms that radically altered the relationship between UK citizens and social security, charging the debate on fairness, conditionality and generosity of payments. Disability benefits, in particular, were reformed to decrease eligibility and increase the quantity and depth of assessment of need. Conditionality and suspicion replaced universalism and giving recipients the 'benefit of the doubt'. This followed the lead of the final term of the New Labour Government, which, via the Welfare Reform Act 2007/ introduced the Work Capability Assessment and replaced Incapacity Benefit with Employment and Support Allowance.

This piece is a collaboration between a behavioural scientist and a policy researcher: the former (DN) bringing knowledge of the evidence on what we know about human social motivations in general; the latter (EJ) bringing concrete experience in developing and evaluating policy in this area. We first describe the reforms to disability benefits in detail, focussing both on the factors that were appealed to in justifying them, and the evidence that they were inefficient and counterproductive. We then turn to the behavioural science. In particular, we discuss why it apparently came so easily to policymakers to develop and sell a focus on suspicion, sanctions and conditionality, even in the absence of detailed evidence that this was needed. This draws us into a more general discussion of the nature of the psychology that voters (and policymakers) bring to the intuitive evaluation of social policies; and, in conclusion, to reflections on the value of the collaboration we have here attempted.

\section{The policy: disability benefits reform}

The reasons for the long-term increase in the numbers of disability benefit claims are no doubt complex, and beyond the scope of this article. We are concerned more with how the Conservative and Liberal Democrat Coalition Government framed the rationale for their reforms; often this carried implications of fraud or, at least, undeserving receipt. For example, although Ministers did not explicitly identify fraud as the formal reason for the replacement of Disability Living Allowance (DLA) - the main disability benefit - with the more stringent and heavily-assessed Personal Independence Payment (PIP), there was substantial discussion of the issue (Department for Work and Pensions 2015). The architect of the reforms, then Work and Pensions Secretary, lain Duncan Smith (Winnett 2012), claimed that: 
We are creating a new benefit, because the last benefit grew by something like 30 percent in the past few years .... It's been rising well ahead of any other gauge you might make about illness, sickness, disability or for that matter, general trends in society.

A lot of that is down to the way the benefit was structured so that it was very loosely defined...Second thing was that in the assessment, lots of people weren't actually seen. They didn't get a health check or anything like that.

Third problem was lifetime awards. Something like 70 per cent had lifetime awards, (which) meant that once they got it you never looked at them again. They were just allowed to fester.

The implication is clear: even if disabled people were not deliberately defrauding the system, many were at least 'undeserving': they were claiming benefits when their level of impairment was not sufficiently significant either to incur additional costs (in the case of PIP and DLA) or when they could be working (in the case of Employment and Support Allowance - ESA). Regular reassessment of all would be the cost of receiving the benefit, and of ensuring that no-one would receive it who did not 'need' it. This implication of fraud or unworthiness suggested a problem that was not supported by available data. When measured in 2004/05, the rate of fraud for Disability Living Allowance was $0.5 \%$, with official error by administrators higher at $0.8 \%$ (Department for Work and Pensions 2019a, Table 2). Interestingly, the rate of fraud for Personal Independence Payment in 2018/19 (i.e. after the reforms) was higher, at 1.6\% (Department for Work and Pensions 2019a, Table 2). If reduction in fraud were the intention, the reforms did not achieve it.

Ministers such as Esther McVey, Parliamentary Under-Secretary of State for Disabled People from September 2012 to October 2013 and Work and Pensions Secretary from January to November 2017, were much more open, and less careful, in revealing the attitudes underlying the reforms. In an interview with the Mail on Sunday, McVey claimed that 'Only three per cent of people are born with a disability, the rest acquire it through accident or illness, but people come out of it. Thanks to medical advances, bodies heal' (Walters 2013). The article went on to claim that:

The decision to introduce new tests has produced an extraordinary 'closing-down sale' effect, with rocketing claims as people rush to get their hands on unchecked 'welfare for life' before McVey's axe falls on April 8. She says Britain simply cannot carry on doling out so much in State handouts. (Walters 2013)

Ironically, many of McVey's comments ran counter to the Office for Disability Issues' commitment to the social model of disability, which focuses on societal barriers to participation and a move away from reliance on medical resolution of impairments (Department for Education, Government Equalities Office and Office for Disability Issues 2015, Appendix 9). As Jenny Morris $(2011,6)$ put it:

This mindset is integrally linked to the promulgation of the idea that an increase in the number of people receiving 'disability' benefits is a sign of increasing 'welfare dependency' rather than a sign of an increasing number of people with impairments and of a society which makes resources available to attempt to create a level playing field.

In 2018, five years after the rollout of PIP began, the Government acknowledged the challenges of regularly reassessing people with 'severe, life-long conditions' by introducing 'ongoing awards' with 
a 'light touch review every 10 years' (Department for Work and Pensions and Newton 2018). This 'common-sense change' removed one of the key distinguishing features of PIP compared to DLA.

The stricter assessment criteria, however, remain largely unchanged from those that initially accompanied the introduction of PIP, except where the Government has been forced to make concessions due to legal action (see Department for Work and Pensions 2020c). The main qualifying criterion for 'enhanced-rate' mobility support in PIP focuses on the distance beyond which applicants cannot walk. ${ }^{1}$ This was reduced from 50 metres under DLA to 20 metres under PIP (Disability Benefits Consortium 2013, 1). This was despite substantial opposition to the move during the consultation on PIP mobility rules (Department for Work and Pensions 2013, 5-7). The Disability Benefits Consortium (DBC), for example, argued that there is evidence that those who can walk for more than 20 metres, but less that the DLA benchmark of 50 metres, face the same additional costs as those unable to walk 20 metres. Examples given include someone unable to walk 50 metres no longer having access to a Motability car despite public transport being more than 20 metres away (Disability Benefits Consortium 2013, 2). Despite this, the Department for Work and Pensions (DWP) $(2013,6-7)$ stated that,

whilst there is no clear evidence for one particular distance, the 20 metre distance was introduced to distinguish those whose mobility is significantly more limited than others and who face even greater barriers on a day-to-day basis - those who have the highest need....

We think it is justified to focus support in this way given the policy intent to target support on those with the greatest need and create a more financially sustainable benefit.

While reduction of the budget deficit and fiscal responsibility were used by then Prime Minister David Cameron and Chancellor George Osborne as justification for the broader austerity agenda (Watt 2013b; Cameron 2009), there is relatively clear evidence that ideology was ultimately driving these changes (Watt, 2013a). This ideology appears to have been driven by a strongly held belief in there being a finite limit to the support government should provide to citizens, with only those 'most in need' given assistance. The direction of travel amongst recent UK Governments has been to move away from universalism wherever possible and pursue greater conditionality and assessment. For example, the once universal Child Benefit, is now only paid in full when neither parent is earning over $£ 50,000$ (Government Digital Service no date). Indeed, even within the current COVID-19 pandemic, universal responses to insecurity, such as Universal Basic Income, have been rejected by the Government (Cowburn and Buchan 2020) in favour of piecemeal, and significantly more complex, assessed forms of support (Government Digital Service 2020).

With regard to PIP, this increasingly conditional approach has failed to achieve the stated policy objective of limiting the amount spent on disability benefits. The Office for Budget Responsibility (2019, 11-12) states that $£ 10.9$ bn was spent on PIP and DLA in $2017 / 18$, which is $f 1-2$ bn more than the likely figure had DLA been retained. Meanwhile, there is a worryingly high success rate in appeals. Three quarters (75\%) of claimants who appeal to a tribunal, following 'mandatory reconsideration' of their decision by the DWP, have their decision overturned in their favour (Department for Work and Pensions 2019b, 9). Overall, approximately 9\% of initial decisions, relating

\footnotetext{
${ }^{1}$ A physically disabled claimant who can walk more than 20 metres can still receive enhanced rate if they also have a mental health, cognitive or sensory impairment that reduces their ability to plan and follow a journey.
} 
to 307,000 individuals, have been overturned at some point in the process. This equates to $39 \%$ of cases submitted for mandatory reconsideration (Department for Work and Pensions 2019b, 10).

The reforms have had an impact beyond administrative complexity and cost. Physical activity provides social, economic, physical and mental health benefits for disabled and non-disabled people (Smith et al., 2018). However, there is evidence that the aggressive conditionality and scrutiny of the current system drives behaviour that harms health and reduces the potential to manage or improve existing conditions and prevent the development of further impairments (see Johnson and Spring 2018; Activity Alliance and IFF Research 2020; Johnson, Degerman and Geyer 2019). Barr et al. (2016) found that Work Capability Assessments were 'independently associated with an increase in suicides, self-reported mental health problems and antidepressant prescribing'.

One impact was termed the Activity Trap by the charity Activity Alliance (see Johnson and Spring 2018). Their research found that $41 \%$ of UK disabled people in receipt of benefits feared that trying to be more active would result in their benefits being withdrawn (Activity Alliance and IFF Research $2020,88)$. Respondents under the age of 40 were 3.4 times as likely as those aged $70+$ to fear loss of benefits or financial support (62\% vs 18\%) (Activity Alliance and IFF Research 2020, 89). The younger group are more likely to have been in receipt of the more stringent PIP and ESA rather than DLA or Attendance Allowance. The psychological impact of conditionality is clear in the finding that around a third of respondents (34\%) would try to be more physically active if their benefits could not be taken away (Activity Alliance and IFF Research, 2020, 91). Half (49\%) of disabled benefit recipients under the age of 50 said they were likely to try to be more active compared to less than a third (29\%) of those aged 50+ (Activity Alliance and IFF Research 2020, 91). As might be expected, almost three in five (56\%) respondents overall said they rely 'very much' on benefits to be active, with those who claim PIP (mobility element) and/or ESA (support group) particularly likely to say this (63\% in each group) (Activity Alliance and IFF Research 2020, 90).

Thus far, those grappling with the apparently unintended consequences of reform, such as the Activity Trap, may not have fully appreciated that these consequences result naturally from Duncan Smith's and McVey's working assumptions on human nature and entitlement. Those assumptions hold that an individual taking part in physical activity no longer requires support, even if this activity fluctuates (see Johnson and Spring 2018), or depends on benefits to take place (Activity Alliance and IFF Research 2020, 90; Smith et al. 2018). The belief that a person who is active cannot be disabled, or at least require benefits, is based on a logical fallacy that, ironically, ignores the rebranding of the Disability Living Allowance to Personal Independence Payment. Rather than the benefit being 'compensation' for an inability to participate, it is the intention of PIP to support disabled people 'to overcome the barriers they face to leading full and independent lives.' (Department for Work and Pensions 2011, 1). Increasing activity that depends on, for example, access to a Motability vehicle, is not evidence that need has reduced. Rather, it is evidence that the intervention is successful and should be maintained. Meanwhile, in terms of fluctuation, even the PIP assessment criteria (Department for Work and Pensions 2019c, 67) acknowledge that:

A scoring descriptor can apply to claimants in an activity where their impairment(s) affects their ability to complete an activity, at some stage of the day, on more than 50 per cent of days in the 12 month period. 
A similar example of disincentivising healthy behaviours and incentivising unhealthy behaviours, is apparent from Johnson, Degerman and Geyer's (2019) study of the relationship between patients and General Practitioners. This demonstrated that welfare recipients may develop strategies to reduce their 'means' by minimising activity and enhance their 'need' by maximising pain-indicating medication. In response to the latter phenomenon, the Government revised guidance to make clear that 'the dosage of painkillers was not necessarily indicative of the severity of people's medical conditions' (BBC News 2019) following a campaign by Bristol Law Centre.

Despite concessions in recent years - such as the introduction of ongoing awards with only 'light touch reviews' and the guidance around assessing the use of opiates - the evidence suggests that the disability benefit reforms have failed to meet the policy objectives set out by the Government. Rather than reduced by an assumed 600,000, the PIP caseload is, in fact, marginally higher than the DLA counterfactual number predicted in 2012 (Office for Budget Responsibility 2019, 12). Meanwhile, stress and hardship have been caused to applicants (see Disability Benefits Consortium 2017), tribunal time has been taken up by incorrect assessment decisions (Department for Work and Pensions 2019b, 9-10), the fraud rate has not identifiably reduced (Department for Work and Pensions 2019a, Table 2) and health promoting activity has been disincentivised (see Johnson and Spring 2018; Activity Alliance and IFF Research 2020, 88-89). The only overarching, measurable policy aim that has been partially achieved is to reduce the number of people eligible for mobility support compared to the DLA counterfactual (Office for Budget Responsibility 2019, 116). The Office for Budget Responsibility $(2019,116)$ stated that:

Higher rate awards are 79,000 (8 per cent) lower than the DLA counterfactual and lower rate awards are 195,000 (21 per cent) lower. However, both are still much higher than the costing assumed, by 349,000 (58 per cent) for the higher rate and 100,000 (16 per cent) for the lower rate.

However, as previously stated, this has not led to a reduction in cost for the benefit overall, with the caseload for the Daily Living component having increased by 100,000 compared with the DLA counterfactual (Office for Budget Responsibility 2019, 116) and the average award around $f 5$ per week higher (Office for Budget Responsibility 2019, 114). The reduction in the mobility component caseload has also only been achieved via the blunt instrument of altering a criterion (the ' 50 metre rule') without evidential justification (Department for Work and Pensions 2013, 6-7). A question raised by Morris $(2011,6)$ has now been answered:

It remains to be seen whether the attempt to reduce the amount of money spent on DLA/PIP will be able, in practice, to successfully (mis-)use the social model to narrow eligibility.

These policy positions - which, as we have seen, did not achieve their desired effects - emerged within a narrative of 'gotcha' moments and binary distinctions between 'scroungers and strivers' (or even 'superhumans' and 'heroes' when referring to Paralympians) (see Briant, Watson and Philo 2011, 8-9; ComRes and English Federation of Disability Sport 2016, 15, 25). We now turn to the question of why this narrative was apparently able to gain traction.

\section{The background: Humans as vigilant cooperators}

In this section, we review recent thinking about the psychological mechanisms underlying giving help to others. This helps us understand why the focus on conditionality and assessment, which we have 
seen was central to the reforms to disability benefits, arose so easily and was so readily accepted as necessary.

Provision of social transfers to disabled people is an example of cooperation, in the sense used in the behavioural sciences: behaviour that benefits someone other than the actor, and is sustained for this reason (West, Griffin and Gardner 2007). This usage of the term 'cooperation' is somewhat different from the everyday usage; paying one's taxes may not feel like 'cooperating', but under the behavioural science definition, it is. Contrary to the direst assumptions about selfish Homo economicus, societies throughout history have involved formal or at least informal arrangements for cooperating, often beyond immediately family (Jaeggi and Gurven 2013). The reason for this, in the most general terms, is that humans are massively interdependent (Nettle et al. 2011; Roberts 2005): they derive myriad benefits from the presence, wellbeing and positive disposition of those around them. Thus, they have incentives for helping one another, and they have evolved strong prosocial motivations that lead them to deliver such help. The existence of these prosocial motivations is a human universal, but their expression varies (Henrich et al. 2010; 2005). For example, the scope of the circle of people potentially eligible for help of different kinds varies with economic and geographical conditions.

The motivation to help others, even when they are members of the relevant social network, is not indiscriminate. First, people's willingness to help is highly sensitive to indications of need (Delton et al. 2018). Such cues indicate a situation where the marginal gain to the recipient from having the resource is larger than the cost to the cooperator of giving it up; it is in exactly these circumstances that giving resources away can be in the cooperator's long-term interest, through future reciprocity or other interdependent benefits of improving the welfare of the recipient (Trivers 1971; Nettle et al. 2011).

Second, many (though not all) kinds of cooperation raise temptations to cheat, for example by signalling need when not really in need, or not making an effort to produce shared resources when there is an opportunity to do so. In evolutionary models, 'cheating' strategies - strategies that take the benefits of the cooperation of others without paying the cost of cooperating themselves - can outcompete unconditionally cooperative ones. This leads to cooperation becoming rare even though it would be mutually beneficial (Axelrod and Hamilton 1981). In the provision of public goods or shared effort, individuals would all be better off if others contributed but they themselves forewent the effort of doing so. This can lead to public goods or shared effort declining, as those who contribute less always end up at a relative advantage (Hardin 1968). In a social network where others are not cooperating, not cooperating leaves one exactly as badly off as everyone else but cooperating whilst others do not do so actually leaves one worse off than everyone else.

Given the potential threat to cooperation from cheating, many authors have stressed that though humans are motivated to be prosocial, they are vigilantly so. Whilst often being prepared to be generous, people are acutely sensitive to cues that others may be cheating or taking more than their due. There are many lines of evidence in support of this position. Without needing training, people perform well on tasks where they have to detect who has broken a social rule, though they perform badly on logically equivalent tasks framed without reference to social cheating (Cosmides 1989). People are highly sensitive to even subtle cues indicating cooperative effort on the part of others, and withdraw their cooperativeness when these indicate that others are not contributing (Keizer, Lindenberg, and Steg 2008, 2013). Likewise, they are sensitive to indications that net beneficiaries 
from cooperation are really in need (Sznycer et al. 2018). Finally, even at direct cost to themselves, people choose to punish those who do not contribute to cooperative efforts but would have been able to do so (Fehr and Gachter 2000).

The consequence of vigilant cooperation is that people attend to and care about the behaviour and intentions of those who receive help. They generally follow the deservingness principle: supporting the transfer of help to those who are deserving, where deservingness is constituted by only requesting help when in genuine need, doing something in return for the help received where possible, and the need not being the outcome of the person's own actions (Van Oorschot 2006; Petersen et al. 2012; Piff et al. 2020). Perceived violation of the deservingness principle triggers anger and the abrupt withdrawal of willingness to help (Petersen et al. 2012). The origins of the deservingness principle may lie in informal interpersonal interactions: in a fluid population, those who are less generous than the deservingness principle would fail to recruit or retain social partners, whilst those who are more generous would be exploited (Debove, Baumard and André 2017). However, people employ the deservingness principle in contexts other than the one in which it evolved, for example when thinking about actual or desirable welfare systems that will be implemented at the scale of a contemporary state (Aaroe and Petersen 2014; Delton et al 2018; Nettle and Saxe 2020).

\section{Folk politics, moral pessimism and cultural attractors}

The account sketched above suggests why many voters would be keen that disability benefits systems should include elements of conditionality and regular assessment for eligibility: they are simply applying their general tendency to be vigilant cooperators. Since vigilant cooperation is presumably an adaptive capacity, this could lead to the argument that conditionality and regular assessment are therefore necessarily good policies. Vigilance is psychologically natural, this argument goes; and psychological naturalness is bound to lead to sensible policy. In this section, we cast doubt on this argument. There are two reasons for being sceptical.

To explain the first reason, it is useful to distinguish between the proper domain of a mechanism, and the actual domain (Sperber 1996). The proper domain is the set of situations a mechanism evolved to deal with, for which it should be reasonably functional. For example, the proper domain of human 3D visual perception is natural scenes and objects. The actual domain is what the mechanism is currently used to process. For example, the actual domain of 3D visual perception for many modern humans includes 3D movies. Here, our perceptual mechanisms can lead us astray, reading things as three-dimensional that really are not, exactly because the mechanisms are operating outside of their proper domain.

The proper domain of our psychological mechanisms for vigilant cooperation is, presumably, fairly small-scale interaction networks within which many or most people knew and encountered each other personally. We assume this to be true simply because such networks have constituted the largest scale of human social organisation for the vast majority of our evolutionary history (Tooby and Cosmides 1992; Boyer and Petersen 2018; Petersen et al. 2012). When vigilant cooperation mechanisms are applied to the actual domain of bureaucratic monitoring systems in large-scale societies, used by people who do not know one another, there is no guarantee that they will lead to systems that are either economically efficient, or achieve their stated goals. This is the problem of 'folk economics' and 'folk politics' (Boyer and Petersen 2018). Intuitive responses to economic and political dilemmas treat those dilemmas as if they were simple dyadic or small-group interpersonal 
interactions, thus failing to foresee inefficiencies, perverse incentives, unimplementability, or emergent negative consequences when those impulses are translated into large-scale formal bureaucratic institutions. For politicians, when choosing between trying to implement expert knowledge - based on extensive modelling, evidence and reasoning, - and folk sentiment that is intuitive but wrong (because applied to an actual domain that differs from its evolved proper domain), there is a temptation to follow folk sentiment, which seems easier to grasp and to sell (Boyer and Petersen 2018).

The second reason for being sceptical that the intuitive appeal of the reforms is any indication of their wisdom is the following. Relying on intuitions about the need for vigilance will only lead to efficient policy if those intuitions are generally accurate. That is, if people's intuitive predictions about the level of cheating likely to exist in a system of social assistance were accurate, they would presumably lead to policies that accorded a due amount of expense to verifying deservingness. However, there is widespread evidence that this may not be so: people consistently expect others to be morally worse than they expect to be themselves (Klein and Epley 2016). They expect others to be more driven by narrow self-interest (Bannerjee and Duflo 2019), and to slack off effort more than they themselves would if provided with resources unconditionally (Dalia Research 2017).

There is, in fact, no guarantee that adaptive means accurate. The apparently systematic pattern of pessimism about the behaviour of others may be an example of what psychologists have described as 'error management' (Haselton and Nettle 2006). Briefly, any detection system can make two kinds of errors: being too sensitive and detecting events that do not in fact happen; or being insufficiently sensitive and failing to detect events that do occur. The optimal balance between these two kinds of errors depends on their relative costs. For example, smoke alarms are engineered to generate many false alarms rather than missing a single true fire. Similarly, if, over evolutionary time, the fitness costs of failing to detect real instances of cheating have tended to be larger than the costs of not trusting where in fact it would have been fine to do so, then the psychological mechanisms underlying cooperation would evolve to be pessimistic. Just like a smoke alarm, it would be easier to trigger them to see cheating than the true level of cheating implied. This would be especially true for individuals we do not know or have rich streams of reassuring first-hand information about. The mind's tendency to see cheating everywhere is, in face-to-face interactions, constantly assuaged by personal observation. For example, prejudice is reduced by direct social interaction (Pettigrew and Tropp 2006; Paluck, Green and Green 2019), and rates of experimental cooperation are sharply increased by allowing participants to communicate personally with one another (Dawes, McTavish and Shaklee 1977; Sally 1995).

Putting these principles together, we can sketch the following speculative account. Politicians and the people they represent are predisposed to accept easily that, absent personal information to the contrary, many people who seek help are not as deserving as they present themselves to be; that this can be detected by enquiring into their behaviour; and that, therefore, the truly deserving ones can be easily separated from the cheaters, and the latter punished. By contrast, they lack intuitions about the negative consequences of suspicion and conditionality, some of which we reviewed for UK disability benefits policy in the first half of the paper. This can lead to a situation where the kinds of institutions that politicians are disposed to propose, and many electors to accept, are not necessarily the kinds that will work best. Systems that spend too much of their effort on vigilance and conditionality, and see cheating and punishment as the central issues, would on this view constitute 
'cultural attractors' (Sperber 1996). Cultural attractors are social forms that are widespread and recurrent, not necessarily because of their efficacy, but because of their appeal to the priors and biases of human psychology.

\section{Solutions: Alternative cultural attractors}

The considerations in the previous section give some explanation for why arguments for increased assessment and conditionality fell on fertile ground after 2010. It fails to explain, however, why the system was ever any different. That is, the cultural attractor argument seems to imply that all welfare systems, everywhere, would converge towards very high levels of conditionality, because of general priors and biases of the human mind. Conditionality is indeed a long-standing principle of need-based assistance (Stone 1984; see next section). Yet clearly, systems do vary substantially across place and time in how they assess, conceptualise, and enforce need. How does this happen? A key principle here is that the psychology underlying cooperation is highly context-sensitive. That is, although there might be psychological impulses towards vigilance and conditionality, there are also other impulses, and different situations lead people to weight the different impulses differently.

For example, people are inclined to greater generosity and less vigilance towards people who are perceived as fundamentally socially similar (Nettle and Saxe 2020). This principle is often discussed in the contexts of racial and ethnic diversity (Alesina, Baqir, and Easterly 1999; Habyarimana et al. 2007). However, 'similarity' is not a natural quantity, but is to a considerable extent created through social contact and through discourse. Likewise, it matters how the resources to be distributed are conceptualised. Quite generally, people are prepared to be more generous and less conditional with resources that they consider as 'windfall' rather than 'earnings' (Carlsson, He, and Martinsson 2010). In cases where resources clearly belong to the class of windfall, societies have had no difficulty implementing completely unconditional systems of social transfer. Examples include the Alaska Permanent Fund, which distributes the windfall of oil royalties (Standing 2017), and distributions of casino royalties in Native American groups (Costello et al. 2003). In the post-war period of rapid economic growth, societies sustained relatively generous safety nets and high marginal rates of taxation. Subsequent retrenchment of assistance and cutting of taxes was linked to an explicit discourse attributing the creation of resources to 'strivers' or 'wealth creators' (Morris 2013), i.e. representing society's resources as individual effort, not social windfall.

Finally, large exogenous events play a major role in how the situation of society is conceived, and hence what kinds of cultural attractors become important. Many authors have stressed how the experience of war paved the way for more inclusive and generous systems of social transfer (Kasza 2006; Obinger and Schmitt 2019). War created interaction between very different people, potentially promoting a sense of similarity; it provided a clearly deserving exogenous reason why many people were disabled or unable to work; and it reinforced the sense that bad luck could strike one house but not the next. This is not necessarily directly relevant to disability benefits in particular as, although the Industrial Injuries Disablement Benefit was introduced in 1948, it was not until the 1970s that a broader and more modern system of disability benefits was instituted in the UK (Burchardt 1999). However, it does illustrate how exogenous events can shift cultural attractors in the domain of social policy. Interestingly, the COVID-19 pandemic appears to have shifted UK and US public opinion sharply away from targeting welfare, and towards the desirability of a universal basic income, perhaps for similar reasons (Nettle et al. 2020). 
For all these reasons, there is no single equilibrium model of need, generosity, conditionality, or sanctions to which all welfare systems are bound to settle. Within broad limits, arguments for greater harshness will win out in some contexts, and arguments for greater latitude or support in others.

\section{Implications: Disability benefits revisited}

We have argued that welfare systems often risk being attracted into counterproductive levels of suspicion and conditionality, as conditionality and cheating is a dog-whistle to the vigilantly cooperating human mind. But, more positively, we have also argued that humans are fundamentally prosocial and respond to need under many circumstances. The key, for policymakers who wish to create and maintain effective systems of social assistance, is to bring about the right perceived set of circumstances.

From the behavioural science evidence reviewed above, we draw out some specific lessons for disability benefits. What these amount to is a reframing of perceptions of welfare. Instead of seeing social transfers as taking resources from one set of people who generate them ('the strivers') to a completely different and separate set, we need to see the welfare system as a way that the common windfall of society is most effectively put to use to benefit the long-term wellbeing of all citizens. We now unpack this general lesson in more specific ways.

First, campaigners should stress the fundamental social similarity of disabled people. Around one in five $(21 \%)$ of the UK population, some 14 million people, are disabled (Department for Work and Pensions, 2020b, Table 4.4). In February 2020, some 3.8 million people were in receipt of one of the two main needs (but not means) assessed disability benefits - Personal Independence Payment or Disability Living Allowance (Department for Work and Pensions, 2020a). Indeed, if we take into account individuals in receipt of any of the main needs-tested benefits (PIP, DLA and Attendance Allowance - for individuals who become eligible aged 65+) and disability-related means-tested benefits (Employment Support Allowance, Incapacity Benefit, Severe Disablement Allowance and Income Support on the basis of incapacity), this amounted to approximately 5.5 million in the quarter to August 2019 (Department for Work and Pensions, 2020d). Indeed, almost half (44\%) of people of state pension age are disabled (Department for Work and Pensions, 2020b, Table 4.1). Therefore, if disability benefits do not directly affect an individual at present, it is very likely that they will in future, or at least a relative or friend.

People who fall under the disability benefits umbrella are, then, not categorically different from most people. Indeed, the same individuals move in and out from under it. Even whilst assisted by it, they contribute to the wealth of society in innumerable ways, both paid and unpaid. Disability benefits are essential to maximising this contribution.

Relatedly, the money spent on disability benefits should not be referred to as a specific 'burden' or cost. Money is spent - or lost in revenue - on a whole raft of interventions, such as tax credits (which are now becoming part of Universal Credit), pensions, the tax-free personal allowance, the Married Couple's Allowance and more. The tax-free personal allowance, for example, is not usually thought of as a benefit or expressed as a cost, but it nonetheless amounts to a financial commitment from the Government. This was made clear by an estimated annual cost of increasing it to $£ 10,000$ by $2014 / 15$ of some $f 10.7$ billion (Institute for Fiscal Studies 2014, 151). Since then, it has increased to $f 12,500$. Disability benefits constitute just one part of a broader system of distribution. 
Finally, although 'folk politics' often pulls in a different direction from expert opinion and analysis, policymaking need not always be reduced to its level. Most people do in fact respond to more extensive reasoning and argumentation (Mercier and Sperber 2017), for example where hard evidence is supplied. Thus, even if the institutional reforms suggested by expert analysis violate people's initial 'folk politics' intuitions, the argument for them can still be made and perhaps won. The best evidence for this comes from the set of processes known as deliberative democracy (Dryzek et al. 2019). The more the populace is drawn deliberatively into institution design, the further from sound-bite folk politics the argument gets, and the more nuanced those institutions can become. Thus, drawing more people more deeply into the policy debate, rather than reducing policy to the lowest common denominator, may lead to policy that is more rational and of greater benefit to the whole of society.

\section{Reflections: The universal and the particular in the analysis of institutions}

Proceeding through a dialogue between two researchers of very different experience and who, day to day, consider data of very different kinds, we have sketched an account of one particular case study. We have suggested why cheating, and the need for greater verification of deservingness, were appealed to and seemed intuitively important in the context of disability benefits policy in the UK, particularly after 2010. It is worth asking the question: to understand a particular place and time, what is the added value of invoking the general psychology of vigilant cooperation, and the idea of cultural attractors? If the psychology is panhuman, then it should apply to 1945 and 1970 as much as 2010, Denmark as well as the UK; it cannot, then, explain much about the differences between the institutions in those places and times, which, for many policy purposes, is what matters.

When the long history of needs-based assistance is written, then the principles we have reviewed will appear as a recurrent theme with ever-shifting fluctuations. These principles include a desire to help, coupled with vigilant concern about deservingness, and the resultant need for procedures to separate the deserving from the undeserving. Indeed, attempts to write that history have come to much this conclusion, without explicit reference to psychological experiments or evolved mechanisms (e.g. Stone 1984; Handler and Hasenfeld 1991). Much of what we have said about vigilant cooperation could apply to the Poor Laws of medieval and early modern England as well as the UK in 2010. That is both the strength, and the weakness, of this level of analysis.

Nonetheless, we do feel that the level of analysis presented here has some merits, even for a specific case like the one we discuss. Our analysis could not have predicted in detail the growth in expenditure on disability benefits from the 1970s onwards; the timing of the rise of neoliberal ideology; the austerity turn of 2010; or the specifics of the post-2010 reforms. However, coupled with some additional explanatory principles, it might offer explanations or at least interpretations at a broader scale. For example: how the post-War period of sustained growth in the UK, and the particular combinations of advanced economic conditions and small populations found in Scandinavia, allowed for a relaxation of vigilance that is more the historical exception than the rule; and how the significant deterioration in economic conditions that occurred the end of the 2000s would result in an increased demand for vigilance, a demand that politicians would find ways of meeting.

More generally, our analysis does suggest at least a heuristic understanding of the intuitive resources political actors draw on when they seek to make changes to society, and how audiences may be susceptible to those appeals. We have also made specific claims about the ways these 
intuitive theories can mislead societies into institutional structures that are not necessarily as efficient or effective as they could be. These claims might, in at least some cases, eventually prove testable and lead to an evidence base for better policies. That is a long way off, but is at least an aspiration for study of folk politics and folk economics (Boyer 2018).

\section{Acknowledgements}

The authors thank John Lazarus, Tom Shakespeare and Matthew Johnson for feedback on this article.

\section{References}

Aaroe, L. and Petersen, M. B. (2014) “Crowding out Culture: Scandinavians and Americans Agree on Social Welfare in the Face of Deservingness Cues', Journal of Politics 76(3): 684-97.

Activity Alliance and IFF Research (2020) Annual Disability and Activity Survey 2019/20. Available at: https://bit.ly/2H4tHf6 (Accessed: 6 February 2020).

Alesina, A. Baqir, R. and Easterly, W. (1999) 'Public Goods Provision and Ethnic Divisions', The Quarterly Journal of Economics 114: 1243-84.

Axelrod, R. and Hamilton, W. D. (1981) 'The Evolution of Cooperation', Science 211: 1390-96.

Bannerjee, A. V. and Duflo, E. (2019) Good Economics for Hard Times. London: Allen Lane.

Barr, B., Taylor-Robinson, D., Stuckler, D., Loopstra, R., Reeves, A. and Whitehead, M. (2016) '“First, do no harm": are disability assessments associated with adverse trends in mental health? A longitudinal ecological study', J Epidemiol Community Health 70: 339.

BBC News (2019) Painkiller campaign leads to benefit claims change. Available at: https://www.bbc.co.uk/news/uk-england-bristol-49958847 (Accessed: 12 February 2020).

Boyer, P. (2018) Minds Make Societies: How Cognition Explains the World Humans Create. New Haven: Yale University Press.

Boyer, P. and Petersen, M. B. (2018) 'Folk Economic Beliefs: An Evolutionary Cognitive Model', Behavioral and Brain Sciences 41: e158.

Briant, E., Watson, N. and Philo, G. (2011) Bad News for Disabled People: How the Newspapers are Reporting Disability. Project Report. Glasgow: Strathclyde Centre for Disability Research and Glasgow Media Unit, University of Glasgow.

Burchardt, T. (1999) The Evolution of Disability Benefits in the UK: Re-weighting the basket. London: Centre for Analysis of Social Exclusion. Available at: http://eprints.Ise.ac.uk/6490/1/The Evolution of Disability Benefits in the UK Reweighting the basket.pdf (Accessed: 31 July 2020).

Cameron, D. (2009) 'David Cameron: We were right to make debt a priority'. The Telegraph, 26 March. Available at: https://www.telegraph.co.uk./news/politics/david-cameron/5052949/Wewere-right-to-make-debt-a-priority.html (Accessed: 16 April 2020).

Carlsson, F., He, H. and Martinsson, P. (2010) 'Windfall vs. Earned Money in the Laboratory : Do They Affect the Behavior of Men and Women Differently?' Gothenberg: Working Papers in Economics 468. 
ComRes and English Federation of Disability Sport (2016) Media Research Report. Available at: http://www.activityalliance.org.uk/how-we-help/research/2236-activity-alliance-media-reportaugust-2016 (Accessed: 11 July 2020).

Cosmides, L. (1989) 'The Logic of Social Exchange: Has Natural Selection Shaped How Humans Reason? Studies with the Wason Selection Task', Cognition 31: 187-276.

Costello, E. J., Compton, S. N., Keeler, G. and Angold, A. (2003) 'Relationships Between Poverty and Psychopathology: A Natural Experiment', Journal of the American Medical Association 290: 2023-29.

Cowburn, A. and Buchan, L. (2020) 'Coronavirus: Chancellor rejects widespread calls for universal basic income, saying government "not in favour"'. The Independent, 24 March. Available at: https://www.independent.co.uk/news/uk/politics/coronavirus-universal-basic-income-rishisunak-ubi-rebecca-long-bailey-a9421281.html (Accessed: 16 April 2020).

Dalia Research. 2017. The EU 's Growing Support for Basic Income. https://basicincome.org/wpcontent/uploads/2017/05/DR-2017-survey.pdf.

Dawes, R. M., McTavish, J. and Shaklee, H. (1977) 'Behavior, communication and assumptions about other people's behavior in a common dilemma situation', Journal of Personality and Social Psychology 35:1-11.

Debove, S., Baumard, N. and Andre, J-B. (2017) 'On the Evolutionary Origins of Equity'. PLOS ONE 12: e0173636.

Delton, A. W., Petersen, M. B., DeScioli, P. and Robertson, T. E. (2018) 'Need, compassion, and support for social welfare', Political Psychology 39:907-924.

Department for Education, Government Equalities Office and Office for Disability Issues (2015) 2010 to 2015 government policy: equality. Available at: https://www.gov.uk/government/publications/2010-to-2015-government-policyequality/2010-to-2015-government-policy-equality\#appendix-9-the-social-model-of-disability (Accessed: 17 April 2020)

Department for Work and Pensions (2011) Disability Living Allowance Reform: Impact Assessment. Available at: https://www.parliament.uk/documents/impact-assessments/IA11-040E.pdf (Accessed: 14 July 2020).

Department for Work and Pensions (2013) The Government's response to the consultation on the PIP assessment Moving around activity. Available at:

https://www.gov.uk/government/consultations/consultation-on-the-pip-assessment-movingaround-activity (Accessed: 26 February 2020).

Department for Work and Pensions (2015) 2010 to 2015 government policy: welfare reform. Available at: https://www.gov.uk/government/publications/2010-to-2015-government-policywelfare-reform/2010-to-2015-government-policy-welfare-reform (Accessed: 2 April 2020).

Department for Work and Pensions (2019a) Fraud and error in the benefit system: financial year 2018 to 2019 estimates - Tables: Fraud and error in the benefit system, 2018 to 2019 estimates. Available at: https://www.gov.uk/government/statistics/fraud-and-error-in-the-benefit- 
system-financial-year-2018-to-2019-estimates (Accessed: 26 February 2020).

Department for Work and Pensions (2019b) Personal Independence Payment: Official Statistics to October 2019. Available at: https://www.gov.uk/government/statistics/personalindependence-payment-april-2013-to-october-2019 (Accessed: 26 February 2020).

Department for Work and Pensions (2019c) PIP Assessment Guide: Part Two - The Assessment Criteria. Available at: https://www.gov.uk/government/publications/personal-independencepayment-assessment-guide-for-assessment-providers (Accessed: 12 July 2020).

Department for Work and Pensions (2020a) DWP benefits statistical summary, February 2020. Available at: https://www.gov.uk/government/publications/dwp-benefits-statistics-february2020/dwp-benefits-statistical-summary-february-2020 (Accessed: 14 April 2020).

Department for Work and Pensions (2020b) Family Resources Survey: financial year 2018/19 Disability data tables. Available at: https://www.gov.uk/government/statistics/familyresources-survey-financial-year-201819 (Accessed: 14 April 2020).

Department for Work and Pensions (2020c) PIP administrative exercise: progress on cases cleared, at 5 January 2020. Available at: https://www.gov.uk/government/publications/pipadministrative-exercise-progress-on-cases-cleared-at-5-january-2020/pip-administrativeexercise-progress-on-cases-cleared-at-5-january-2020 (Accessed: 21 April 2020).

Department for Work and Pensions (2020d) Stat-Xplore: Benefit Combinations dataset: August 2019. Available at: https://stat-xplore.dwp.gov.uk (Accessed: 14 April 2020).

Department for Work and Pensions and Newton, S. (2018) Government to end unnecessary PIP reviews for people with most severe health conditions. Available at: https://www.gov.uk/government/news/government-to-end-unnecessary-pip-reviews-forpeople-with-most-severe-health-conditions (Accessed: 8 June 2020).

Disability Benefits Consortium (2013) DBC Briefing: The PIP 20 Metre Rule. Available at: https://www.visionuk.org.uk/download/archive 1/docs/DBC PIP 20 metre rule briefing.doc (Accessed: 26 February 2020).

Disability Benefits Consortium (2017) Supporting those who need it most? Evaluating Personal Independence Payment. Available at: https://disabilitybenefitsconsortium.files.wordpress.com/2017/09/supporting-those-whoneed-it-most-full-report.pdf (Accessed: 9 July 2020).

Dryzek, J. S., Bächtiger, A., Chambers, S., Cohen, J., Druckman, J. N., Felicetti, A., Fishkin, J. S., Farrell, D. M., Fung, A., Gutmann, A., Landemore, H., Mansbridge, J., Marien, S., Neblo, M. A., Niemeyer, S., Setälä, M., Slothuus, R., Suiter, J., Thompson, D., Warren, M. E. (2019) 'The crisis of democracy and the science of deliberation', Science 363, 1144-46.

Fehr, E. and Gachter, S. (2000) 'Cooperation and Punishment in Public Goods Experiments', The American Economic Review 90: 980-94.

Government Digital Service (no date) Claim Child Benefit. Available at: https://www.gov.uk/childbenefit/eligibility (Accessed: 2 April 2020). 
Government Digital Service (2020) Support for those affected by COVID-19. Available at: https://www.gov.uk/government/publications/support-for-those-affected-by-covid19/support-for-those-affected-by-covid-19 (Accessed: 16 April 2020).

Habyarimana, J., Humphreys, M., Posner, D. N. and Weinstein, J. M. (2007) 'Why Does Ethnic Diversity Undermine Public Goods Provision?', American Political Science Review 101: 709-25.

Handler, J. and Hasenfeld, Y. (1991) The Moral Construction of Poverty: Welfare Reform in America. Sage: Newbury Park.

Hardin, G. (1968) 'The Tragedy of the Commons', Science 162: 1243-48.

Haselton, M. G. and Nettle, D. (2006) 'The Paranoid Optimist: An Integrative Evolutionary Model of Cognitive Biases', Personality and Social Psychology Review 10(1): 47-66. DOI: 10.1207/s15327957pspr1001_3.

Henrich, J., Boyd, R., Bowles, S., et al. (2005) "'Economic man" in cross-cultural perspective: behavioral experiments in 15 small-scale societies', Behavioral and Brain Sciences 28:795-815.

Henrich, J., Ensminger, J., McElreath, R., et al. (2010) 'Markets, religion, community size, and the evolution of fairness and punishment', Science 327:1480-4.

Institute for Fiscal Studies (2014) The Green Budget 2013. London: Institute for Fiscal Studies. Available at: https://www.ifs.org.uk/green-budget/2014 (Accessed 4 June 2020).

Jaeggi, A. V. and Gurven, M. (2013) 'Natural Cooperators: Food Sharing in Humans and Other Primates', Evolutionary Anthropology 22(4): 186-95.

Johnson, A. (2009) 'Letters: Why Professor David Nutt was shown the door', The Guardian, 2 November. Available at: https://www.theguardian.com/politics/2009/nov/02/drug-policy-alanjohnson-nutt (Accessed: 28 January 2020).

Johnson, E. and Spring, E. (2018) The Activity Trap, Manchester: Activity Alliance. Available at: http://www.activityalliance.org.uk/how-we-help/research/4404-the-activity-trap-benefits-orbeing-fit (Accessed: 6 April 2020).

Johnson, M. T., Degerman, D., Geyer, R. (2019) 'Exploring the health case for a trial of Universal Basic Income', Basic Income Studies 14(2): 1-11. DOI: 10.1515/bis-2019-0008.

Kasza, G. J. (2006) 'War and Welfare Policy in Japan', The Journal of Asian Studies 61: 417-35.

Keizer, K. Lindenberg, S. and Steg, L. (2008) 'The Spreading of Disorder', Science 322: 1681-85.

Keizer, K, Lindenberg, S. and Steg, L. (2013) 'The Importance of Demonstratively Restoring Order', PIOS ONE 8: e65137.

Klein, N. and Epley, N. (2016) 'Maybe Holier, but Definitely Less Evil, than You: Bounded SelfRighteousness in Social Judgment.' Journal of Personality and Social Psychology 110(5): 660-74.

Mercier, H. and Sperber, D. (2017) The Enigma of Reason. Cambridge, MA: Harvard University Press.

Morris, J. (2011) Rethinking disability policy. York: Joseph Rowntree Foundation. Available at: https://www.jrf.org.uk/sites/default/files/jrf/migrated/files/disability-policy-equality- 
summary.pdf (Accessed: 20 April 2020).

Morris, N. (2013) 'It's a stunt! lain Duncan Smith dismisses demands to live on $f 53$ a week', The Independent, 3 April. Available at: https://www.independent.co.uk/news/uk/politics/its-astunt-iain-duncan-smith-dismisses-demands-to-live-on-53-a-week-8556985.html (Accessed: 4 June 2020).

Nettle, D. Johnson, E. Johnson, M. and Saxe, R. (2020) 'Why Has the COVID-19 Pandemic Increased Support for Universal Basic Income?' PsyArXiv. DOI: 10.31234/osf.io/csr3u.

Nettle, D, Panchanathan, K., Rai, T. S. and Fiske, A. P. (2011) 'The Evolution of Giving, Sharing, and Lotteries.' Current Anthropology 52(5): 747-56.

Nettle, D, and Saxe, R. (2020) 'Preferences for Redistribution Are Sensitive to Perceived Luck, Social Homogeneity, War and Scarcity.' Cognition 198: 104234.

Obinger, H. and Schmitt, C. (2019) 'World War and Welfare Legislation in Western Countries', Journal of European Social Policy. DOI: 10.1177/0958928719892852.

Office for Budget Responsibility (2019) Welfare trends report. Available at: https://obr.uk/wtr/welfare-trends-report-january-2019 (Accessed: 18 February 2020).

Paluck, E.L, Green, S.A. and Green, D.P. (2019). The contact hypothesis re-evaluated. Behavioural Public Policy 3: 129-58.

Petersen, M. B., Sznycer, D., Cosmides, L. and Tooby, J. (2012) 'Who Deserves Help? Evolutionary Psychology, Social Emotions, and Public Opinion about Welfare', Political Psychology 33(3): 395-418.

Pettigrew, T.F. and Tropp, R.L. (2006) A meta-analytic test of intergroup contact theory. Journal of Personality and Social Psychology 90: 751-83.

Piff, P.K., Wiwad, D., Robinson, A.R., Aknin, L.B., Mercier, B., Shariff, A. (2020) 'Shifting attributions for poverty motivates opposition to inequality and enhances egalitarianism', Nature Human Behaviour 4: 496-505. DOI: 10.1038/s41562-020-0835-8.

Roberts, G. (2005) 'Cooperation through Interdependence', Animal Behaviour 70(4): 901-8.

Sally, D. (1995) 'Conversation and cooperation in social dilemmas: A meta-analysis of experiments from 1958 to 1992, Rationality and Society 7:58-92.

Smith, B., Kirby, N., Skinner, B., Wightman, L., Lucas, R. and Foster, C. (2018) Physical activity for general health benefits in disabled adults: summary of a rapid evidence review for the UK Chief Medical Officers' update of the physical activity guidelines. London: Public Health England. Available at: https://www.gov.uk/government/publications/everybody-active-every-day-aframework-to-embed-physical-activity-into-daily-life (Accessed: 6 April 2020).

Sperber, D. (1996) Explaining Culture: A Naturalistic Approach. Oxford: Blackwell.

Standing, G. (2017) Basic Income: And How We Can Make It Happen. London: Pelican.

Stone, D. (1984) The Disabled State. Philadelphia: Temple University Press. 
Sznycer, D., Delton, A. W., Robertson, T. E., Cosmides, L. and Tooby, J. (2018) 'The Ecological Rationality of Helping Others: Potential Helpers Integrate Cues of Recipients' Need and Willingness to Sacrifice', Evolution and Human Behavior 40(1): 34-45. DOI: 10.1016/i.evolhumbehav.2018.07.005.

Travis, A. (2009) 'Chief drug adviser David Nutt sacked over cannabis stance', The Guardian, 30 October. Available at: https://www.theguardian.com/politics/2009/oct/30/david-nutt-drugsadviser-sacked (Accessed: 28 January 2020).

Trivers, R. L. (1971) 'The Evolution of Reciprocal Altruism', The Quarterly Review of Biology 46: 3557.

Van Oorschot, W. (2006) 'Making the Difference in Social Europe: Deservingness Perceptions among Citizens of European Welfare States', Journal of European Social Policy 16(1): 23-42.

Walters, S. (2013) 'I will go after bogus disabled... some of them DO get better! Ex-TV host who is our new Work Minister on the UK's THREE MILLION claiming disability benefit.' The Mail on Sunday, 30 March. Available at: https://www.dailymail.co.uk/news/article-2301735/I-bogusdisabled--DO-better-Ex-TV-host-new-Work-Minister-UKs-THREE-MILLION-claiming-disabilitybenefit.html (Accessed: 17 April 2020).

Watt, N. (2013a) 'David Cameron makes leaner state a permanent goal'. The Guardian, 12 November. Available at: https://www.theguardian.com/politics/2013/nov/11/david-cameronpolicy-shift-leaner-efficient-state (Accessed: 16 April 2020).

Watt, N. (2013b) 'David Cameron: UK must go further and faster on reducing deficit'. The Guardian, 27 February. Available at: https://www.theguardian.com/politics/2013/feb/27/david-cameronuk-reducing-deficit (Accessed: 16 April 2020).

West, S. A., Griffin, A. S. and Gardner A. (2007) 'Social Semantics: Altruism, Cooperation, Mutualism, Strong Reciprocity and Group Selection', Journal of Evolutionary Biology 20(2): 415-32.

Winnett, R. (2012) ' 500,000 to lose disability benefit'. The Telegraph, 13 May. Available from: https://www.telegraph.co.uk/news/health/news/9263453/500000-to-lose-disabilitybenefit.html (Accessed: 23 February 2020). 